\title{
Sex and the city: reflexões sobre a representação parlamentar feminina e as eleições municipais de 2008
}

\author{
Patrícia Duarte Rangel \\ Doutoranda em Ciência Política (Universidade de Brasília) \\ Brasília, Brasil \\ pdrangel@gmail.com
}

\begin{abstract}
Resumo Os acadêmicos começaram a se interessar pelo envolvimento e pela contribuição das mulheres na arena social e política bastante recentemente. Em muitas instituições, os chamados "estudos de gênero" não são bem recebidos e não é raro que os especialistas nessa área sejam veladamente marginalizados. Se olharmos para as teorias sociais, vamos nos deparar com uma profunda lacuna sobre o papel feminino na análise política, que se mostra difícil de reverter. Este artigo tem a intenção de contribuir, ainda que modestamente, para ampliar o corpo de análises acerca da presença feminina na política institucional e de sua participação como candidatas nas eleições municipais. $\mathrm{O}$ objetivo é analisar a inserção das mulheres no Legislativo municipal e seu desempenho na disputa pela Câmara dos Vereadores nos três últimos pleitos no Brasil. O método escolhido é a perspectiva comparada, e o foco será a eleição de 2008, ainda que dados das eleições de 2004 e 2000 também sejam apresentados. As variáveis utilizadas são sistemas eleitorais, fatores socioeconômicos, culturais e outros aspectos políticos.
\end{abstract}

Palavras-chave: estudos de gênero; eleições; representação feminina; Poder Legislativo.

\section{Introdução}

CEXO E A CIDADE. As mesmas palavras que nomeiam um famo$\checkmark$ so seriado americano, empregadas com outra conotação, serviram de inspiração para este artigo. Como o sexo de um candidato altera substancialmente suas chances de eleição? Até que ponto ser homem ou mulher agrega legitimidade para o exercício da função política na cidade? De onde vêm os mitos acerca da inaptidão feminina para lidar com a coisa pública e como os mecanismos institucionais perpetuam tais ideias? Há saída para isso? É em torno dessas questões que se desenvolveram os parágrafos que se seguem.

Não é novidade que categorias puramente naturais produzem efeitos em instituições sociais, mas as formas como isso se processa parecem muitas vezes encobertas por um véu de fumaça. Daí a necessidade de produzir trabalhos que explorem e explicitem os principais aspectos desse fenômeno. Atendendo à demanda, este texto aborda tal questão em sua expressão política. Analisaremos aqui a participação feminina nos últimos três pleitos municipais do país (cargos legislativos), numa perspectiva comparada. O foco principal será a eleição de 2008, mas também 
utilizaremos dados das eleições de 2004 e 2000 como parâmetros para desenvolver reflexões sobre o pleito mais recente. Em todos os casos, poucas foram as candidatas que obtiveram sucesso, e, a cada eleição realizada, menos mulheres são eleitas vereadoras em termos percentuais. A lei de cotas, por sua vez, não parece ter influenciado positivamente, apesar de ser um mecanismo de ação afirmativa para mulheres por princípio.

A parte introdutória deste trabalho apresentará um breve panorama da representação parlamentar feminina no Brasil e no mundo, além de abordar a relevância de cargos legislativos no âmbito municipal e a competição eleitoral, incluindo a argumentação acerca da necessidade da eleição de mulheres. A seguir, apresentaremos três grandes problemas encontrados nas eleições em questão: 1) a ínfima eleição de mulheres nos municípios de uma forma geral (Executivo e Legislativo), apontando como explicação fatores socioeconômicos e culturais; 2) a sub-representação parlamentar feminina e o decréscimo percentual de vereadoras eleitas; 3) a face institucional do problema, focando nas deficiências da lei eleitoral. Nas considerações finais, abordaremos a necessidade de uma reforma política para aprofundar o processo de feminização do Legislativo.

O ponto de partida deste artigo, e sua principal fonte, são os estudos do Cfemea ${ }^{1}$ sobre a participação das mulheres nas eleições municipais de 2008 (Rangel, 2008a e 2008b), 2004 (Rodrigues \& Boselli, 2004a, 2004b) e 2000 (Cfemea, 2000). O conjunto de análises da instituição utiliza dados do Tribunal Superior Eleitoral (TSE).

Reunidas as desventuras das incontáveis mulheres que se lançam em uma querela marcadamente sexista tal qual a disputa eleitoral, temos uma epopeia que renderia mais que as aventuras amorosas que encontramos quando interpretamos sexo e cidade num sentido estereotipado do papel social feminino, como é o caso de Sex and the city.

\section{O Legislativo municipal: quem representa e o que representa?}

Em fevereiro de 2009, a média de mulheres parlamentares era $18,4 \%$ no mundo e $21,5 \%$ nas Américas, segundo a União Interparlamentar (IPU, 2009a). O Brasil, com 9\% de mulheres na Câmara dos Deputados (9 em 513) e 12,3\% no Senado (10 em 91), estava na $106^{\mathrm{a}}$ posição de um ranking composto por $136 \mathrm{pa}-$ íses (IPU, 2009b).
Esse baixo percentual é problemático não só por ferir um dos princípios básicos da representação proporcional $1^{2}$ - a noção de "microcosmo" contida na definição de representação simbólica, que busca reproduzir a configuração da sociedade nos parlamentos - e, portanto, por gerar um déficit democrático. Ele é problemático também por diminuir as chances de atender demandas da coletividade feminina, uma vez que os principais formuladores de políticas públicas para as mulheres comuns são as próprias mulheres legisladoras.

Falando no Legislativo municipal, podemos sintetizar as funções de vereadores e vereadoras nas seguintes tarefas: representar interesses da população em geral, aprovar leis assegurando o desenvolvimento da coletividade, fiscalizar e controlar gastos públicos e avaliar ações da prefeitura. Uma vez que a implementação de legislação e programas essenciais para mulheres depende da ação do município, a presença feminina nas assembleias municipais se faz extremamente relevante. Como legisladoras, as mulheres podem suscitar o debate sobre a importância de políticas voltadas para elas, monitorar o cumprimento das normas (principalmente da Lei Maria da Penha) e instruir a população, além de efetivamente propor projetos e buscar recursos para a viabilização de eventos que debatam questões de gênero.

Apesar de ser clara a necessidade da presença feminina nas assembleias municipais, o que observamos na realidade é uma imensa resistência a esse movimento. Os partidos políticos, de uma forma geral, não estimulam sua participação nas eleições e raramente preenchem as cotas para o sexo minoritário. Entre os critérios dos líderes partidários para o recrutamento de candidatos estão: qualificações formais dos aspirantes, experiência prévia em cargos eletivos, vínculos políticos, recursos financeiros e fama. Assim, possuindo capital político e visibilidade, uma mulher tem grandes chances de ser recrutada, o que não se relaciona à vontade política de diminuir a disparidade de gênero e sim a uma competição eleitoral que valoriza os que já estão prontos para a campanha.

Contudo, o perfil das candidatas não corresponde majoritariamente ao tipo ideal dos partidos: as mulheres costumam ter trajetória recente e pouca visibilidade. É por isso que os partidos políticos não se preocupam em promover a liderança feminina de forma ampla. Eles selecionam as mulheres com capital político alto para competir com chances de ganhar e convocam outras para preencher as cotas e somar votos. De uma maneira geral, candidatas comuns (que não têm os recursos políticos desejados) são deixadas de lado em detrimento de candidatos comuns (igual-

1 O Cfemea - Centro Feminista de Estudos e Assessoria - é uma organização não governamental, sem fins lucrativos, que trabalha pela cidadania das mulheres e pela igualdade de gênero.

2 Sistema pelo qual deputados e vereadores são eleitos no Brasil. 
mente desprovidos de tais atributos). Assim, muitas mulheres que pensam em se candidatar acabam desistindo, pois não contam com o apoio do partido nem suporte financeiro suficiente.

Em grande medida, a sub-representação parlamentar feminina, tanto no âmbito federal quanto no local, deve-se às singularidades do sistema político-eleitoral brasileiro, questão que analisaremos mais adiante. A adoção da lista aberta e a forte individualização das campanhas políticas fazem com que as mulheres enfrentem incontáveis dificuldades para entrar no jogo com possibilidades reais de eleição. A ausência de penalidades para o não cumprimento da lei de cotas acaba tornando inúteis as estratégias voltadas para monitorar sua aplicação. A racionalidade e a transparência do recrutamento de candidatos(as) dependem do estabelecimento de regras claras e da disposição dos partidos para cumprirem-nas, o que raramente ocorre no Brasil. No país, a seleção de candidatos é feita predominantemente no "jardim secreto" das decisões de elites partidárias, no qual quem manda são os homens.

Sobre o caráter elitista de nosso sistema políticoeleitoral, cabe comentar a influência que os recursos materiais dos candidatos exercem sobre suas chances de eleição. O caráter individualizado da disputa eleitoral inerente ao sistema de lista aberta incentiva a competição entre aspirantes dentro de um mesmo partido ou coligação, lançando-os numa busca por recursos próprios, sejam eles financeiros, de mídia, de pessoal ou de contatos. Além de uma consequência natural do tipo de lista, a personalização da política ocorre porque os recursos dos quais os partidos dispõem para as campanhas (o fundo partidário) são insignificantes perante seus custos. Essa característica da lógica eleitoral é uma barreira quase instransponível para as candidaturas femininas.

Sem recursos financeiros, a decisão de construir uma carreira política é muito mais onerosa para mulheres do que para homens. Podemos afirmar que o afastamento generalizado das mulheres do jogo eleitoral se deve, em grande parte, a fatores de natureza socioeconômica. Citamos como problema central o alto grau de desigualdade na divisão sexual do trabalho social, que agrava a desmobilização das mulheres. Sabendo que um homem é o principal responsável pelos afazeres domésticos em apenas $2 \%$ dos domicílios (Venturi \& Recamán, 2005), podemos compreender, ao menos em parte, por que as mulheres permanecem fora da política institucional: com o acúmulo dos trabalhos remunerado e não remunerado, elas carregam o peso de uma dupla jornada de trabalho e não dispõem de tempo ou incentivo para se envolver em atividades partidárias, que implicam uma tripla jornada (trabalho doméstico, trabalho remunerado e militância partidária).

Também representa um obstáculo para elas o fato de muitos homens com carreiras políticas consolida- das conseguirem facilmente se reeleger. A reeleição é um fator de conservação da composição de gênero e um obstáculo à renovação da Câmara de Vereadores. Entre outros motivos, é por isso que as mulheres demoram mais para construir uma carreira política. Além dos fatores econômicos, características da cultura brasileira interferem negativamente na relação entre mulheres e política eleitoral.

É inquestionável que as desigualdades de gênero em todos os âmbitos da sociedade persistem e que, apesar das conquistas importantes da coletividade feminina, a força dos valores patriarcais não diminuiu substancialmente. Certas desigualdades não são percebidas como injustas, e grande parcela da população brasileira ainda considera que existem atividades distintas para homens e mulheres (Sorj, 2005). A primeira barreira à participação política feminina já aparece em casa: a educação acaba sendo contaminada pelo sexismo ainda na mais tenra infância.

Em geral, as meninas crescem condicionadas a pensar que são diferentes dos meninos, que não têm as mesmas qualidades, que não podem se envolver em certos tipos de atividades "masculinas". Quando chegam à idade adulta, elas se deparam com a política institucional como uma dessas atividades proibidas e se sentem intimidadas para atuar fora dos bastidores. Os dados que analisaremos em seguida do processo eleitoral que terminou em outubro de 2008 ilustram tudo isso.

\section{Eleições municipais 2008: poucas mulheres eleitas, menos demandas femininas contempladas}

Partindo dos resultados das eleições municipais disponibilizados pelo Tribunal Superior Eleitoral (TSE) e sistematizados pelo Cfemea (Rangel, 2008a e 2008b), foi possível cruzar determinadas variáveis e sistematizar conclusões acerca da participação das mulheres. A impressão geral que passa a análise dos resultados é que o poder político institucional continua sendo masculino, branco e proprietário.

No citado pleito, apesar de maioria do eleitorado (51,73\% dos 130.604 .430 de eleitores), as mulheres foram minoria das candidaturas a prefeito, vice-prefeito e vereador (21,36\% dos 377.733) nos 5.558 municípios em que houve votação. Por consequência, foram minoria dos(as) eleitos(as). Para se ter uma ideia, dos 15.231 candidatos(as) a prefeito(a), 1.621 (10,64\%) eram mulheres, sendo que entre os 5.555 eleitos(as), elas eram somente 504 (9,07\%).

Em relação ao Legislativo municipal, o engajamento feminino foi superior ao Executivo na etapa das candidaturas - houve 76.670 mulheres candidatas à 
Tabela 1: Grau de instrução de candidatos(as) a vereador(a) por sexo - Brasil, 2008 (\%)

\begin{tabular}{|l|l|l|l|}
\hline Grau de instrução & Homens & Mulheres & Total \\
\hline Analfabeto & 87,13 & 12,87 & 100 \\
\hline Ensino fundamental completo & 82,36 & 17,64 & 100 \\
\hline Ensino fundamental incompleto & 86,12 & 13,88 & 100 \\
\hline Ensino médio completo & 75,75 & 24,25 & 100 \\
\hline Ensino médio incompleto & 79,18 & 20,82 & 100 \\
\hline Lê e escreve & 87,50 & 12,50 & 100 \\
\hline Superior completo & 66,61 & 33,39 & 100 \\
\hline Superior incompleto & 73,05 & 26,95 & 100 \\
\hline TOTAL & 77,93 & 22,07 & 100 \\
\hline
\end{tabular}

Fonte: Cfemea/ Eleições 2008.

vereadora entre os 347.333 candidatos(as) $(22,07 \%)$-, mas o percentual de eleitas não acompanhou a média de candidatas: houve somente 6.508 vereadoras eleitas em um total de 51.965 (12,52\%). Esses dados, por si só, já servem de indício para apontar que as mulheres são mantidas à margem da política institucional.

Cabe destacar, contudo, que a disputa eleitoral é excludente por natureza e tende a manter minorias políticas afastadas. A coletividade feminina não é a única a sofrer com a marginalização: jovens, negros, classes desfavorecidas economicamente, todos enfrentam grandes dificuldades como candidatos. Observemos por exemplo o perfil das(os) candidatas (os) ${ }^{3}$ a vereador(a) de 2008 em termos geracionais: enquanto a maior parte $(39,22 \%)$ tinha entre 45 a 59 anos, a faixa etária em que havia menos candidaturas era aquela entre os 18 e os 20 anos (7,35\%). Observamos também que os homens eram maioria em todas as faixas etárias (Rangel, 2008a).

Cruzando o recorte de gênero com o de geração, pudemos notar diferença especialmente marcante: os candidatos homens eram maioria esmagadora nas faixas entre 60 e 69 anos (81,81\%), 70 e 79 anos (87,44\%) e superior a 79 anos $(89,98 \%)$. A faixa etária em que a disparidade de gênero foi menos acirrada era de 18 a 20 anos (67,05\% homens e 32,95\% mulheres). Talvez isso esteja associado aos ciclos de vida da mulher e às consequências da divisão sexual do trabalho. Mais jovens, as mulheres não têm obrigações e compromissos relacionados à família e, portanto, a militância partidária ainda não implica uma tripla jornada de trabalho nesta fase inicial da vida adulta.

Em relação ao recorte racial e socioeconômico, também pesa mais para as mulheres o fator preconceito de cor/etnia. Isso porque a sub-representação política feminina é transpassada por um sistema de exclusão que se expressa em diversas formas de marginalização, sobretudo econômica e racial. As mulheres não são excluídas dos espaços de decisão só por serem mulheres, mas por serem maioria da população pobre e por não serem, em grande medida, pertencentes ao grupo étnico dominante.

Como vimos, a cultura também é um fator que contribui para a marginalização feminina na esfera pública: é bem clara a resistência por parte dos partidos políticos e do eleitorado em relação à eleição de mulheres como representantes legítimos. Os eleitores não parecem, por exemplo, utilizar os mesmos parâmetros para homens e mulheres na hora de avaliar as capacidades de seu candidato. Altos níveis de educação, que em geral constituem condição favorável para ascender a cargos legislativos, são mais comuns entre as candidatas e, mesmo assim, não maximizam as chances das candidaturas femininas. Vejamos os dados das eleições municipais de 2008: os homens foram maioria numérica em cada faixa na classificação do grau de instrução dos candidatos a vereador, assim como ocorre nas demais categorias. Desta forma, apresentaram maiores percentuais de educação formal do que as mulheres em números absolutos (Tabela 1).

Entretanto, tal superioridade masculina no grau de escolaridade é puramente numérica e só ocorre porque o número absoluto de homens candidatos é superior ao de mulheres. Se separarmos os dados e calcularmos o percentual de candidatos em cada faixa sobre o total de candidaturas de cada sexo, teremos a Tabela 2 e a Tabela 3.

Enquanto o grupo de mulheres candidatas mais representativo é o das que terminaram o ensino médio $(34,84 \%)$, seguido do grupo das que terminaram o ensino superior $(25,27 \%)$, o grupo de homens candidatos mais representativo é o dos que terminaram o ensino médio $(30,83 \%)$, seguido dos que não terminaram o ensino fundamental $(24,20 \%)$. Os homens que terminaram o ensino superior são só $14,28 \%$, bem menos do que os $25,27 \%$ de mulheres que o fizeram.

Esses dados apontam que as mulheres apresentam atributos acadêmicos superiores aos homens e, ain- 
Tabela 2: Grau de instrução de candidatos homens a vereador - Brasil, 2008

\begin{tabular}{|l|r|r|}
\hline Grau de instrução & \multicolumn{2}{|c|}{ Homens } \\
\hline & Quant. & $\%$ \\
\hline & & \\
\hline Analfabeto & 237 & 0,09 \\
\hline Ensino fundamental completo & 44.313 & 16,37 \\
\hline Ensino fundamental incompleto & 65.491 & 24,20 \\
\hline Ensino médio completo & 83.452 & 30,83 \\
\hline Ensino médio incompleto & 16.342 & 6,04 \\
\hline Lê e escreve & 8.769 & 3,24 \\
\hline Superior completo & 38.645 & 14,28 \\
\hline Superior incompleto & 13.414 & 4,96 \\
\hline TOTAL & 270.663 & 100 \\
\hline
\end{tabular}

Fonte: Cfemea/ Eleições 2008.

da assim, o eleitorado dá preferência às candidaturas masculinas. Com tamanha resistência à ascensão de mulheres a cargos de decisão, demandas femininas são mais dificilmente contempladas, uma vez que a população em questão não é satisfatoriamente representada. Não queremos dizer que mais mulheres na política gerariam automaticamente mais políticas públicas para a coletividade feminina. Afinal de contas, não basta eleger mais mulheres e sim mais mulheres com consciência de gênero, ou seja, cientes de sua situação de marginalização e dispostas a fortalecer a solidariedade com base na ideia de que a desigualdade é estrutural e que as soluções devem ser coletivas.

É preciso, portanto, haver a combinação de uma política de presença (mais mulheres) com uma política de ideias (consciência de gênero, fim da desigualdade, aprofundamento da democracia). Esse argumento nos permite demandar maior incorporação de mulheres em cargos legislativos sem presumir que a simples inclusão se traduza em preferências ou interesses co-
Tabela 3: Grau de instrução de candidatas mulheres a vereadora - Brasil, 2008

\begin{tabular}{|l|r|r|}
\hline Grau de instrução & \multicolumn{2}{|c|}{ Mulheres } \\
\hline & Quant. & 0,05 \\
\hline Analfabeto & 35 & 12,38 \\
\hline Ensino fundamental completo & 9.491 & 13,77 \\
\hline Ensino fundamental incompleto & 10.557 & 34,84 \\
\hline Ensino médio completo & 26.712 & 5,60 \\
\hline Ensino médio incompleto & 4.296 & 1,63 \\
\hline Lê e escreve & 1.253 & 25,27 \\
\hline Superior completo & 19.376 & 6,46 \\
\hline Superior incompleto & 4.950 & 100 \\
\hline TOTAL & 76.670 & \\
\hline
\end{tabular}

Fonte: Cfemea/ Eleições 2008.

muns, nem que uma assembleia legislativa mais equilibrada do ponto de vista do gênero contemple temas de relevância para a cidadania feminina.

\section{Poucas vereadoras eleitas em 2004, menos mulheres ainda em 2008}

Em se falando de formulação de políticas públicas, cabe aqui lançar um olhar mais atencioso sobre a situação das legisladoras municipais de um ponto de vista histórico, ou seja, verificar se o desempenho das aspirantes a vereadoras tem evoluído progressivamente ao longo das últimas eleições. Almira Rodrigues e Giane Boselli, no estudo do Cfemea sobre as eleições de 2004 (Rodrigues \& Boselli, 2004b), observaram que, apesar de ampliarem suas posições como prefeitas naquele pleito, as mulheres mantiveram sua presença proporcio-

Tabela 4: Homens e mulheres eleitos(as) vereadores(as) em números absolutos e percentuais - Brasil, 2000-2008

\begin{tabular}{|c|r|r|r|r|r|r|}
\hline Ano & Homens eleitos & $\%$ & Mulheres eleitas & $\%$ & Total eleitos & $\%$ \\
\hline 2000 & 53.266 & 88,35 & 7.001 & 11,61 & 60.287 & 100 \\
\hline 2004 & 45.238 & 87,33 & 6.555 & 12,65 & 51.800 & 100 \\
\hline 2008 & 45.457 & 87,48 & 6.508 & 12,52 & 51.965 & 100 \\
\hline
\end{tabular}

Fonte: Cfemea/ Eleições 2008. 
nal nas Câmaras de Vereadores, tendo inclusive havido redução no número absoluto de suas cadeiras.

Naquele ano, foram 6.556 vereadoras $(12,65 \%)$, 446 a menos que em 2000, quando foram eleitas 7.001 mulheres $(11,61 \%){ }^{4}$ Tal sintoma foi verificado novamente em 2008, pleito no qual se constatou uma diminuição de 47 mulheres e um crescimento de 219 homens eleitos(as) em relação às eleições de 2004. Ou seja, houve decréscimo percentual de mulheres eleitas $(0,72 \%)$ e crescimento percentual de homens eleitos $(0,48 \%)$. Podemos constatar, portanto, que o número absoluto de vereadoras eleitas vem decaindo desde 2000 , ao passo que o mesmo só aconteceu para os homens em 2004, como se vê na Tabela $4^{5}$ (Rangel, 2008b).

O curioso de 2008 é que houve crescimento considerável de prefeitas eleitas, cargo escolhido em eleição majoritária que não é contemplada pelo sistema de cotas: elas subiram de 407 prefeitas em $2004(7,35 \%)$ para $504(9,07 \%)$, o que representa um crescimento absoluto de 95 cadeiras e um crescimento proporcional de 23,83\% (Rangel, 2008b). O mesmo se verificou no caso das candidatas: para os cargos executivos disputados nas eleições municipais de 2008 (prefeito(a)), as candidatas subiram de $9,53 \%$ para $10,64 \%$, enquanto para cargos legislativos (vereador(a)), as candidatas desceram de $22,13 \%$ para 22,07\% (Rangel, 2008a).

Ou seja, tem sido verificado maior êxito de eleição das candidatas mulheres em cargos executivos, apesar de a lei de cotas contemplar somente a disputa de cargos legislativos em eleições proporcionais. Esse fenômeno de diminuição das vereadoras aponta para a falta de eficácia das cotas e para o caráter meramente simbólico que parece ter o sistema de ação afirmativa: nenhum dos 27 partidos políticos cumpriu a lei eleitoral que reserva um percentual mínimo de 30\% das vagas de candidatura ao sexo minoritário. ${ }^{6}$

\section{Cotas para candidaturas femininas: anjo ou demônio?}

A legislação eleitoral brasileira, como acabamos de ver, estabelece uma cota para o sexo minoritário nas vagas de candidaturas: a Lei $n{ }^{\circ} .9 .504 / 97$ (Art. $10, \sqrt{\int} 3^{\circ}$ ) reserva no mínimo $30 \%$ e no máximo $70 \%$ das vagas de candidaturas para cada sexo, em eleições proporcionais. ${ }^{7}$ É importante ressaltar que a cota é aplicada às candidaturas, não ao número de cadeiras em cada assembleia. Havendo tal ferramenta institucional, o natural seria que as mulheres se candidatassem e se elegessem mais como vereadoras do que como prefeitas. Contudo, como vimos, o que se verificou nas últimas três eleições municipais foi crescimento substantivo de prefeitas (e candidatas a prefeitas) e não de vereadoras (e candidatas).

A norma já é falha por natureza, pois designa às mulheres somente $30 \%$ das vagas nas listas eleitorais num país em que mais da metade da população é composta por mulheres. A lei é insuficiente em transferir para as assembleias legislativas a realidade da sociedade. Além disso, não estabelece sanções ou mecanismos que garantam o cumprimento das cotas. O máximo de punição para os partidos que violam a legislação é o impedimento de preencher os 30\% mínimos destinados às mulheres com candidaturas masculinas. Para piorar, a Lei no $.9 .504 / 97$ permite ao partido "registrar candidatos para a Câmara dos Deputados, Câmara Legislativa, Assembleias Legislativas e Câmaras Municipais, até cento e cinqüenta por cento do número de lugares a preencher", o que abre margem para aumentar o número de candidaturas masculinas e deixar de lado as femininas.

Exemplo: se há 100 vagas em determinada Câmara dos Vereadores, cada partido poderia, a princípio, oferecer 100 candidatos, sendo que no mínimo 30 seriam mulheres. Contudo, a brecha oferecida pela lei permite que sejam oferecidos 150 candidatos, com 45 mulheres, no mínimo. Como o partido não é punido em caso de descumprimento e pode deixar em aberto as 45 vagas femininas, ele simplesmente oferece 105 homens e nenhuma mulher para disputar as 100 vagas, sem violar nenhuma norma. Ou seja, a mesma lei que reserva cotas para mulheres providencia o mecanismo para neutralizar seus efeitos.

O que podemos concluir é que o sistema de cotas não tem apresentado efeitos diretos sobre as candidaturas femininas a cargos legislativos. Desprovido de poder de enforcement, ele é caracterizado mais como forma de influenciar indiretamente a disputa e incentivar a discussão sobre a necessidade de ampliação da participação política das mulheres para o aprofundamento da democracia. Nesse sentido, comprova-se sua eficácia, com o crescimento progressivo do percentual/número absoluto de prefeitas eleitas.

Apesar dos problemas encontrados na aplicação da lei de cotas, é importante ressaltar o valor desse mecanismo de ação afirmativa, seu efeito simbólico, sua in-

4 A queda, em números absolutos, do total de eleitos em 2004 se deveu à redução no número de cadeiras nas Câmaras Legislativas (elas diminuíram em mais de 8.000, intensificando a competição entre os(as) candidatos(as).

5 Não foram incluídos nesta tabela os dados de pessoas de sexo não informado, daí o motivo pelo qual determinadas linhas não fecham em $100 \%$. 60 maior percentual de mulheres candidatas foi 23,83\% (PRB).

7 Eleições para vereador(a), deputado(a) federal e deputado(a) estadual. Presidente, governadores(as), prefeitos(as) e senadores(as), por sua vez, são eleitos por uma fórmula majoritária e, por isso, não há aplicação da cota. 
fluência nas transformações da cultura política de modo a aceitar cada vez mais a presença feminina e a conquista que ele representa para o movimento feminista e para a coletividade de mulheres brasileiras. $\mathrm{O}$ fato de haver dificuldades indica a necessidade de aprimorar o sistema, não de descartá-lo. Poder-se-ia, por exemplo, modificar o tipo de lista eleitoral, de forma a garantir boas chances de eleição para as mulheres.

\section{Conclusões: os benefícios de uma reforma política para a representação feminina}

Sendo aproximadamente metade da população e $52 \%$ do eleitorado, não há lógica no fato de haver pouco mais de $12 \%$ de mulheres vereadoras no país. Se a lei de cotas é falha, insuficiente ou facilmente neutralizada e existe um grave problema de representação feminina no Brasil, é preciso modificá-la ou substituí-la. Mais que isso, é preciso transformar o sistema eleitoral e o sistema político brasileiro como um todo. Isso porque a baixa representação feminina não diz respeito somente às mulheres, diz respeito à democracia: a proporção de mulheres em cargos legislativos tem sido cada vez mais apontada como indicador da qualidade da representação política e critério para mensurar a democracia. Podemos falar em déficit democrático no Legislativo, pois uma assembleia só é considerada representativa se sua composição for uma miniatura da sociedade. Uma vez que há aproximadamente $50 \%$ de cidadãs e quase nada de legisladoras, é porque não há representação de fato. O mesmo ocorre para outros grupos sociais historicamente marginalizados.

O Brasil faz parte de uma família do sistema eleitoral favorável (representação proporcional), mas seu tipo de lista é apontado como adverso à eleição de mulheres. A lista aberta permite uma mobilização de tipo vertical (reordenamento intrapartidário) e autoriza ainda uma mobilização de tipo horizontal (reagrupamento interpartidário), possibilitando que o eleitor modifique a ordem dos candidatos na lista e incorpore nomes de outros partidos políticos. A lista fechada, ao contrário, tem a vantagem de impedir que se anule o preordenamento de uma lista confeccionada com observância de alternância de sexo, uma vez que o eleitor não pode alterar a ordem dos nomes dos candidatos na folha de votação. Por esse motivo, muitos estudiosos argumentam que as cotas por sexos apresentam maio- res chances de obter sucesso quando são aplicadas em sistemas de lista fechada, como na Argentina, do que em lista aberta, como no Brasil. ${ }^{8}$ A lista aberta rompe acordos e equilíbrios que se tentam alcançar no âmbito político institucional, além de tornar o processo eleitoral personalizado.

Daí a demanda do movimento feminista para que se instaure no Brasil um sistema que adote listas fechadas com alternância de sexo e que se estabeleça um preordenamento (impedindo que os homens fiquem em sequência nos melhores lugares), colocando as mulheres no topo da lista (com maiores chances de eleição). As sugestões feministas para alterar as regras do jogo eleitoral foram sintetizadas no documento Ponto de vista da reforma feminista sobre reforma política (Cfemea, 2006) e podem ser esquematizadas da seguinte forma:

- a adoção de listas de candidatura fechadas com alternância de sexo e observância de critérios étnico-raciais e geracionais;

- a destinação de 30\% do tempo da propaganda eleitoral gratuita às mulheres;

- o financiamento público exclusivo das campanhas eleitorais (para combater a corrupção nos processos eleitorais e a privatização política);

- a reserva de 30\% do fundo partidário para candidaturas femininas;

- paridade de participação entre os sexos, garantindo $50 \%$ das vagas para mulheres.

Além de uma reforma política que contemple as mulheres, as feministas também demandam que os compromissos, a legislação e as propostas já existentes para incrementar a presença feminina em espaços de poder sejam postos em prática. A Constituição Federal de 1988, por exemplo, proíbe todo e qualquer tipo de discriminação de gênero, além de estabelecer que "homens e mulheres são iguais em direitos e obrigações" (Art. 5\%, I). O II Plano Nacional de Políticas Para as Mulheres - PNPM (Secretaria Especial de Políticas para as Mulheres, 2008), por sua vez, tem como objetivo geral "promover e fortalecer a participação igualitária, plural e multirracial das mulheres nos espaços de poder e decisão" e, como objetivos específicos, "estimular a ampliação da participação das mulheres nos cargos de decisão dos poderes constituídos (Executivo, Legislativo e Judiciário) em todos os níveis, respeitando-se os recortes de raça/etnia" e "inserir no debate da reforma política o tema da paridade na representação parlamentar".

Entre as metas do II PNPM estavam a garantia da plena aplicação da Lei 9.504/97 e a ampliação em 
Quadro 1: Comparação entre proposta do Executivo e propostas do movimento feminista para uma reforma política

\begin{tabular}{|l|l|}
\hline Demanda feminista & Proposta do Executivo contempla? \\
\hline Financiamento público exclusivo de campanhas eleitorais & Sim, mas há problemas (partidos pequenos com parcela irrisória) \\
\hline Listas preordenadas de candidaturas & $\begin{array}{l}\text { Em parte. (Prevê somente } 30 \% \text { de cotas para mulheres em metade } \\
\text { da lista) }\end{array}$ \\
\hline Diminuição ou fim da cláusula de barreira & $\begin{array}{l}\text { Em parte. 1\% dos votos válidos em eleição para a Câmara + 0,5\% dos } \\
\text { votos em, pelo menos, 1/3 dos Estados }\end{array}$ \\
\hline Fidelidade partidária & Em parte. Permite em caso de perseguição, mudança, partido novo \\
\hline Ações afirmativas & Não \\
\hline
\end{tabular}

20\% da participação de mulheres nas Câmaras de Vereadores em 2008. Essas metas claramente não foram alcançadas. A realidade, ao contrário, mostra que não houve avanço na incorporação de mulheres à política institucional e no recrutamento de candidatas em 2008. A análise dos resultados dessas eleições e de tantas outras nos demonstra que, enquanto não houver uma reforma no sistema político, a desigualdade entre homens e mulheres não será superada.

No segundo semestre de 2008, os ministros Tarso Genro e José Múcio Monteiro Filho elaboraram um anteprojeto de reforma política que foi submetido à apreciação do Congresso Nacional. A minuta não contemplava a demanda das mulheres por maior participação na política institucional, deixando de lado suas sugestões, como podemos ver no Quadro 1. A proposta de lista fechada sugeria que cada partido garantisse, "ao menos na primeira metade de sua lista partidária, a existência de ambos os gêneros a cada três candidatos sob pena de indeferimento do registro da respectiva lista”. Ora, 30\% de cotas em 50\% resultam numa reserva menor que a legislação atual.

\section{Referências}

ARAÚJO, Clara. Mujeres y elecciones legislativas en Brasil: las cuotas y su (in) eficácia. In: ARCHENTI, N.; TULA, M.I. (Eds.). Mujeres y política en América Latina. Sistemas electorales y cuotas de género. Buenos Aires: Heliasta, 2008.

Percepções e atitudes de mulheres e homens sobre a conciliação entre família e trabalho pago no Brasil. In:. ARAÚJO, C.; SCALON C. (Orgs.) Gênero, família e trabalho no Brasil. Rio de Janeiro: Editora FGV, 2005.

ARCHENTI, Nélida; TULA, María Inés. Algunas cuestiones iniciales sobre las leyes de cuotas. In: ARCHENTI, N.; TULA, M.I.(Eds.) Mujeres y politica en América Latina. Sistemas electorales y cuotas de género. Buenos Aires: Heliasta, 2008.

AVELAR, Lúcia. Mulheres na elite política brasileira. São Paulo: Fundação Konrad Adenauer: Editora da Unesp, 2001.

CFEMEA. Ponto de vista da reforma feminista sobre reforma política. Disponível em http://www.cfemea.org.br/publicacoes/publicacoes_detalhes.asp?IDLivro=26. Acesso em: 1. dez. 2008.
Apesar de avançar em relação à legislação eleitoral atual, propondo um sistema de sanções para o não cumprimento da norma (indeferimento da lista), o projeto encontra nesse ponto o único fator de retrocesso do documento inteiro. Ele falha em "tratar desigualmente os desiguais, buscando-se a justiça social", meta estabelecida no II PNPM pelo mesmo Executivo do qual os ministros fazem parte.

Com base em tudo o que foi explorado neste artigo, a sugestão para reflexão que deixamos é amadurecer a ideia da reforma política como forma de ampliar a participação das mulheres na esfera pública. Talvez quando parte dos compromissos já estabelecidos e dos que ainda surgirão for colocada em prática, as palavras sex and the city não nos remeta mais a aventuras fúteis de mulheres exercendo o papel tradicionalmente estabelecido para o seu sexo, mas sim a uma nova realidade, na qual a competência e o esforço feminino possam ser valorizados e exercidos na política. Que essas palavras nos remetam a um tempo em que o sexo não interfira nas chances de chegar ao poder, e que este seja exercido igualmente por mulheres e homens.
_-_-_-_- . Dados estatísticos. Eleições 2000. Disponível em http://www.cfemea.org.br/temasedados/detalhes. asp? IDTemasDados=23. Acesso em: 1. dez. 2008.

INTER-PARLIAMENTARY UNION . Women in parliaments: situation as of 28 Freburary 2009 - world average. Disponível em http://www.ipu.org/wmn-e/world.htm, Acesso em: 20 mar. 2009a.

INTER-PARLIAMENTARY UNION (2009b). Women in parliaments: situation as of 28 February 2009 - world classification. Disponível em http://www.ipu.org/wmn-e/ classif.htm. Acesso em: 20 mar. 2009b.

MARX, Jutta; BORNER, Jutta; CAMINOTTI, Mariana. Las legisladoras: cupos de género y política en Argentina y Brasil. Buenos Aires: Siglo XXI Editora Iberoamericana, 2007.

RANGEL, Patrícia. Mulheres e eleições 2008: náufragas em um oceano de machos. Disponível em http://www.cfemea. org.br/temasedados/detalhes.asp? IDTemasDados $=216$. 
Acesso em: 1. dez. 2008a.

Balanço das eleições municipais e desempenho das mulheres candidatas. Disponível em http://www.cfemea. org.br/temasedados/detalhes.asp? IDTemasDados $=218$. Acesso em: 1. dez. 2008b.

RODRIGUES, Almira; BOSELLI, Giane. Balanço das eleições 2004 - Mulheres candidatas. Disponível em http://www.cfemea.org.br/temasedados/detalhes. asp?IDTemasDados=73. Acesso em: 1. fev. 2009a.

Balanço das eleições 2004 - Mulheres eleitas.

Disponível em http://www.cfemea.org.br/temasedados/detalhes.asp?IDTemasDados=76. Acesso em: 1. fev. 2009b.
SECRETARIA ESPECIAL DE POLITICAS PARA AS MULHERES. II Plano Nacional de Políticas Para as Mulheres, disponível em http://www.11conferenciadh.com.br/ arquivos/deliberacoes/2plano_pol_mulheres.pdf. Acesso em: 1. fev. 2009.

SORJ, Bila. Percepções sobre esferas separadas de gênero. In:. ARAÚJO, C.; SCALON C. (Orgs.) Gênero, família e trabalho no Brasil Rio de Janeiro: Editora FGV, 2005.

VENTURI, Gustavo; RECAMÁN, Marisol. As mulheres brasileiras no início do século 21. Disponível em http://www2. fpa.org.br/portal/modules/news/article.php?storyid $=700$. Acesso em: 9. jan. 2009.

\title{
Sex and the city: reflections on women's parliamentary representation and the 2008 municipal elections
}

\begin{abstract}
Scholars have only recently started paying attention to the involvement and contribution of women in the social-political arena. In several institutions, the so-called "gender studies" are not exactly welcomed and it is not rare to find that specialists in the field are secretly marginalized. Examining the variety of existing social theories, we can clearly see that the female role lacks in space in political analysis and this situation is not easily addressed. This article intends to contribute to the efforts to increase the body of studies regarding women's institutional presence in politics and their participation as candidates in local municipal elections. The article is also aimed at analyzing the input of women in the local legislative branch and their improvement/efficiency in the Town Hall (Câmara dos Vereadores) elections in the last three polls. The comparative perspective is the method of choice, and the focus rests on the 2008 elections, however the 2004 and 2000 polls will also be studied. The variables used are electoral systems, social, economical and cultural factors, as well as other political aspects.
\end{abstract}

Key words: Gender studies; elections; female representation; legislative branch.

\section{Sex and the City: Reflexiones sobre la representación parlamentar femenina y las elecciones municipales de 2008}

\begin{abstract}
Resumen
Los académicos empezaron a interesarse por el enredamiento y contribución de las mujeres a la arena social y política bastante recientemente. En muchas instituciones, los llamados "estudios de género" no son bien recibidos y no es raro que los especialistas en esa área sean veladamente marginalizados. Si estudiamos las teorías sociales, vamos nos deparar con un profundo hueco sobre el papel femenino en el análisis político que se muestra difícil de revertir. Este artículo posee la intención de contribuir, aunque modestamente, para ampliar el cuerpo de análisis sobre la presencia femenina en la política institucional y su participación como candidatas en las elecciones municipales. Su objetivo es analizar la inserción de las mujeres en el Legislativo municipal y su desempeño en la disputa por la Cámara de los Concejales en los tres últimos pleitos en Brasil. El método elegido es la perspectiva comparada y el foco será la elección de 2008, aunque datos de las elecciones de 2004 y 2000 también sean presentados. Las variables utilizadas son sistemas electorales, factores socioeconómicos, culturales y otros aspectos políticos.
\end{abstract}

Palabras clave: estudios de género; elecciones; representación femenina; Poder Legislativo. 
